\title{
An Approach to Detect and Mitigate Ice Particle Accretion in Aircraft Engine Compression Systems
}

Ryan D. May

Vantage Partners, LLC, Cleveland, Ohio

Ten-Huei Guo and Donald L. Simon

Glenn Research Center, Cleveland, Ohio 


\section{NASA STI Program . . . in Profile}

Since its founding, NASA has been dedicated to the advancement of aeronautics and space science. The NASA Scientific and Technical Information (STI) program plays a key part in helping NASA maintain this important role.

The NASA STI Program operates under the auspices of the Agency Chief Information Officer. It collects, organizes, provides for archiving, and disseminates NASA's STI. The NASA STI program provides access to the NASA Aeronautics and Space Database and its public interface, the NASA Technical Reports Server, thus providing one of the largest collections of aeronautical and space science STI in the world. Results are published in both non-NASA channels and by NASA in the NASA STI Report Series, which includes the following report types:

- TECHNICAL PUBLICATION. Reports of completed research or a major significant phase of research that present the results of NASA programs and include extensive data or theoretical analysis. Includes compilations of significant scientific and technical data and information deemed to be of continuing reference value. NASA counterpart of peer-reviewed formal professional papers but has less stringent limitations on manuscript length and extent of graphic presentations.

- TECHNICAL MEMORANDUM. Scientific and technical findings that are preliminary or of specialized interest, e.g., quick release reports, working papers, and bibliographies that contain minimal annotation. Does not contain extensive analysis.

- CONTRACTOR REPORT. Scientific and technical findings by NASA-sponsored contractors and grantees.
- CONFERENCE PUBLICATION. Collected papers from scientific and technical conferences, symposia, seminars, or other meetings sponsored or cosponsored by NASA.

- SPECIAL PUBLICATION. Scientific, technical, or historical information from NASA programs, projects, and missions, often concerned with subjects having substantial public interest.

- TECHNICAL TRANSLATION. Englishlanguage translations of foreign scientific and technical material pertinent to NASA's mission.

Specialized services also include creating custom thesauri, building customized databases, organizing and publishing research results.

For more information about the NASA STI program, see the following:

- Access the NASA STI program home page at http://www.sti.nasa.gov

- E-mail your question to help@sti.nasa.gov

- Fax your question to the NASA STI Information Desk at 443-757-5803

- Phone the NASA STI Information Desk at 443-757-5802

- Write to: STI Information Desk NASA Center for AeroSpace Information 7115 Standard Drive Hanover, MD 21076-1320 


\section{An Approach to Detect and Mitigate Ice Particle Accretion in Aircraft Engine Compression Systems}

Ryan D. May

Vantage Partners, LLC, Cleveland, Ohio

Ten-Huei Guo and Donald L. Simon

Glenn Research Center, Cleveland, Ohio

Prepared for the

Turbo Expo 2013

sponsored by the American Society of Mechanical Engineers (ASME)

San Antonio, Texas, June 3-7, 2013

National Aeronautics and

Space Administration

Glenn Research Center

Cleveland, Ohio 44135 


\section{Acknowledgments}

The authors would like to thank the NASA Aviation Safety Program's Vehicle Systems Safety Technologies Project for funding this work.

Level of Review: This material has been technically reviewed by technical management.

Available from

NASA Center for Aerospace Information 7115 Standard Drive

Hanover, MD 21076-1320
National Technical Information Service 5301 Shawnee Road Alexandria, VA 22312

Available electronically at http://www.sti.nasa.gov 


\title{
An Approach to Detect and Mitigate Ice Particle Accretion in Aircraft Engine Compression Systems
}

\author{
Ryan D. May \\ Vantage Partners, LLC \\ Cleveland, Ohio 44135 \\ Ten-Huei Guo and Donald L. Simon \\ National Aeronautics and Space Administration \\ Glenn Research Center \\ Cleveland, Ohio 44135
}

\begin{abstract}
The accretion of ice in the compression system of commercial gas turbine engines operating in high ice water content conditions is a safety issue being studied by the aviation sector. While most of the research focuses on the underlying physics of ice accretion and the meteorological conditions in which accretion can occur, a systems-level perspective on the topic lends itself to potential near-term operational improvements. This work focuses on developing an accurate and reliable algorithm for detecting the accretion of ice in the low pressure compressor of a generic 40,000 lbf thrust class engine. The algorithm uses only the two shaft speed sensors and works regardless of engine age, operating condition, and power level. In a 10,000-case Monte Carlo simulation, the detection approach was found to have excellent capability at determining ice accretion from sensor noise with detection occurring when ice blocks an average of 6.8 percent of the low pressure compressor area. Finally, an initial study highlights a potential mitigation strategy that uses the existing engine actuators to raise the temperature in the low pressure compressor in an effort to reduce the rate at which ice accretes.
\end{abstract}

\section{Introduction}

Over the past twenty years, there have been approximately 150 reported cases of aircraft engine power loss due to the accretion of ice crystal particles in the compression system of commercial turbofan engines (Ref. 1). The majority of the work in response to this aviation safety concern has focused on understanding the mechanism by which particles in high icewater content (HIWC) conditions can accrete on compressor stator blades, understanding the environmental conditions in which accretion can occur, and related regulatory questions (Ref. 2). While redesigning the compressor to prevent ice accretion is the ideal long-term solution, a systems-level analysis highlights some near-term capabilities.

Previous work has developed a means to simulate the impact of ice accretion in the low pressure compressor (LPC) using a series of stacked compressor maps (Ref. 3). When these maps are integrated into a high-fidelity engine simulation, the overall system response to the presence of ice can be simulated
(Ref. 4). Using this approach, a method to detect the accretion of ice using only the existing engine sensors is proposed.

For this work, the engine simulation known as C-MAPSS40k (the Commercial Modular Aero-Propulsion System Simulation 40,000 lbf) is used (Ref. 5). This simulation is written in MATLAB/Simulink and is a generic, modular, physics-based simulation of a 40,000 lbf thrust-class engine. This simulation is used due to the fact that it is based on dynamic flight test data, includes a realistic engine controller (Ref. 6), and realistic sensor noise models (Ref. 7).

The stack of "iced" LPC maps is integrated into C-MAPSS40k and the user is given an input through which the ice blockage level of the LPC can be specified (between 0 and 27 percent). The LPC operating point is then linearly interpolated to lie between the operating points of the two nearest maps. In this manner, the user can change the blockage level as a function of time to simulate the accretion of ice in the LPC second stator row.

A previously developed engine ice particle accretion detection technique (Ref. 8) relied on observing shifts in the engine sensor outputs directly. While this approach was reasonably effective (97.94 percent true positive rate, 0.10 percent false positive rate, and mean detection occurs at 5.519 percent blockage), the false positive rate (false alarm rate) was much too high for use in service. Thus, a detection technique aimed at directly detecting the change in LPC performance is developed. To determine the performance of this new algorithm, it is applied to the C-MAPSS40k engine simulation and a Monte Carlo study is conducted and evaluated against three detection metrics (true positive rate, false positive rate, and mean blockage at detection).

This work then begins to investigate potential strategies to mitigate the accretion of ice. It is believed that there is a small range of temperatures at which the ice particles can accrete in the compressor (Ref. 9) and by changing the engine operating point away from this temperature, the ice growth can be mitigated or prevented. Various strategies to change the LPC temperature are investigated using existing engine actuators in both typical and novel ways.

The next section will describe the detection algorithm in general followed by the specifics of the algorithm when applied to C-MAPSS40k. The detection work is concluded with the results of the Monte Carlo analysis and a discussion of the 
performance of the detection algorithm. A brief section on potential means to mitigate the accretion of ice is then given followed by some conclusions.

\section{Nomenclature}

\begin{tabular}{|c|c|}
\hline C-MAPSS40k & Commercial Modular Aero-Propulsion \\
\hline & System Simulation 40,000 lbf \\
\hline EPR & Engine pressure ratio \\
\hline $\mathrm{F}_{\text {net }}$ & Net engine thrust \\
\hline$H$ & Fault influence coefficient matrix \\
\hline HIWC & High Ice Water Content \\
\hline $\mathrm{HPC}$ & High Pressure Compressor \\
\hline LPC & Low Pressure Compressor \\
\hline $\mathrm{LPC}_{\mathrm{eff}}$ & LPC efficiency parameter \\
\hline $\mathrm{LPC}_{\text {flow }}$ & LPC flow capacity parameter \\
\hline $\begin{array}{l}\mathrm{Nc}_{\mathrm{c} 2} \\
\text { conditions }\end{array}$ & Core shaft speed corrected to inlet \\
\hline $\mathrm{Nf}_{\mathrm{c} 2}$ & Fan shaft speed corrected to inlet conditions \\
\hline$R$ & Sensor noise covariance matrix \\
\hline ROC & Receiver Operating Characteristic \\
\hline $\mathrm{T}_{25}$ & LPC outlet gas temperature \\
\hline VBV & Variable Bleed Valve \\
\hline VSV & Variable Stator Vane \\
\hline$w$ & Sensor noise vector \\
\hline$x$ & Vector of LPC health parameters \\
\hline$\hat{x}$ & Estimated vector of LPC health parameters \\
\hline$y$ & Vector of sensor residuals \\
\hline
\end{tabular}

\section{Detection Algorithm}

Based on the simulation results given in Reference 3 and summarized in the LPC maps shown in Figure 1, ice accretion results in a change in compressor efficiency and a loss of flow capacity. The loss of flow capacity can be observed directly from the maps by noting that the speed lines shift to the left (lower corrected flow rate) as the size of the ice blockage increases. Typically there is a loss of compression, which can be seen as a downwards shift in the speed lines. However, for operating points near the surge line, there are cases where the efficiency does not change or even increases. In order to determine when ice accretion is occurring, the engine sensors can be used to estimate these shifts. In order to apply this detection algorithm as widely as possible, only the two shaft speed sensors are used.

In order to develop an algorithm that could feasibly operate on an existing commercial aircraft engine, the algorithm is designed to be computationally simple and have a minimal

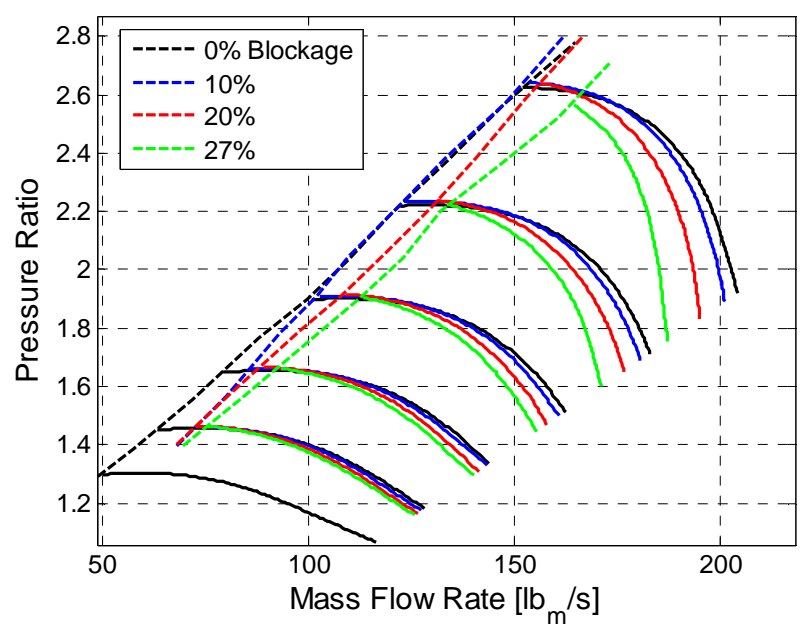

Figure 1.-LPC maps used to simulate the impact of ice blockage in the second row stators. Reproduced from (Ref. 8) based on data from (Ref. 3). Surge lines (dashed) and speed lines (solid) are shown.

memory footprint. This rules out many of the common approaches in on-board diagnostics such as model-based designs and Kalman-filter based algorithms (Ref. 7). Rather, a simple linear estimator is used to estimate the LPC performance characteristics.

A critical assumption of this approach is that the engine inlet conditions (altitude and Mach number) and the throttle must be quasi-steady-state. This assumption means that any change in the sensor outputs can be attributed to a change in engine operation (due to ice accretion or some other fault). In order to determine when the conditions are appropriate to use this ice detection approach, there are steady-state detection algorithms (Ref. 10) that can be used to trigger the ice detection routine.

A flow chart of the detection algorithm is shown in Figure 2. The remainder of this section will walk through each step of the process.

Once the engine inlet conditions and throttle are determined to be quasi-steady, the fan and core shaft speed sensor outputs are corrected then processed into two different signals: a longwindow time-averaged signal and a current value. The difference between these two signals is called a sensor residual and contains information related to short time-scale changes in engine performance. This approach allows the algorithm to "ignore" the effects of engine aging, engine-to-engine variation, and other slight differences in the turbomachinery that must be addressed in model-based designs.

These sensor residuals can be expressed as a function of LPC parameters as shown in Equation (1). The variable $y$ is a vector of sensor residuals. The vector of LPC parameters (efficiency and flow capacity) is $x$, and the matrix $H$ is called the fault-influence coefficient matrix. The input $w$ is zeromean sensor noise with covariance matrix $R$.

$$
y=H x+w
$$




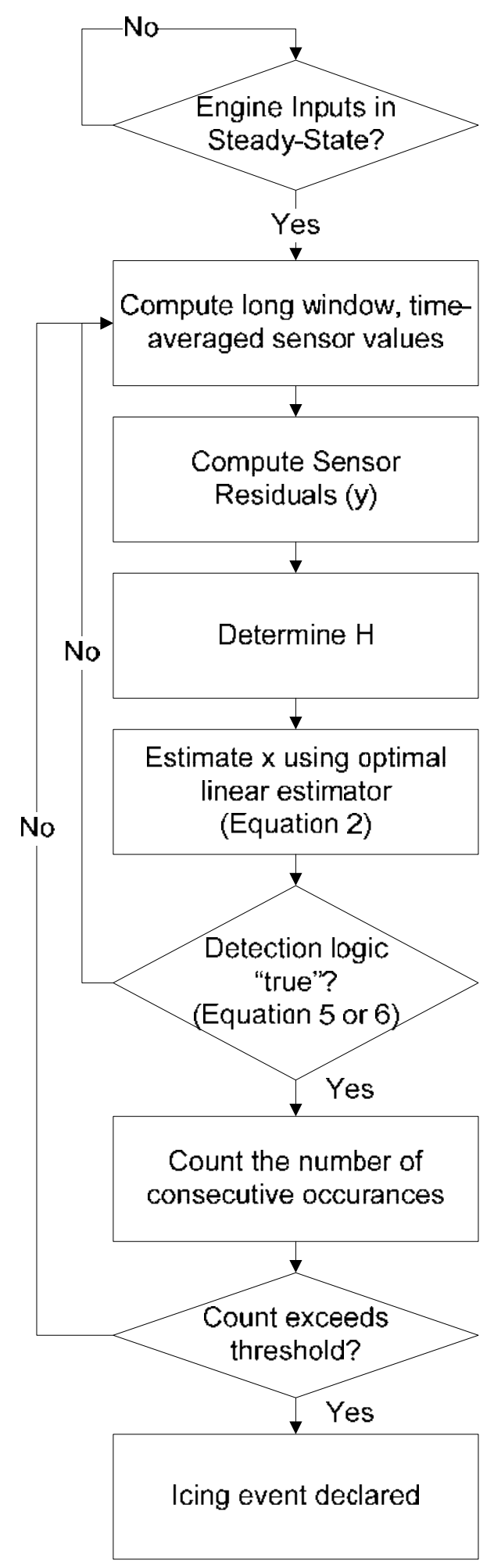

Figure 2.-Flow of the ice accretion detection algorithm used in this paper. This process is conducted every controller time step.
The LPC parameters used here are typically referred to as health parameters $\left(\mathrm{LPC}_{\text {eff }}\right.$ and $\left.\mathrm{LPC}_{\text {flow }}\right)$ and are commonly used in health detection, monitoring, and estimation tasks. For example, if the $\mathrm{LPC}_{\text {eff }}$ has a value of 0.01 , this means that there is a 1 percent increase in the efficiency of the LPC. A value of -0.02 for $\mathrm{LPC}_{\text {flow }}$ means that there is a 2 percent decrease in LPC flow capacity.

The detection algorithm seeks to determine when LPC performance changes are occurring by monitoring for changes in the LPC health parameters. Although not directly measurable, an estimate of the LPC health parameter vector, $\hat{x}$, can be obtained by applying a weighted least squares estimation technique (Ref. 11) given as:

$$
\hat{x}=\left(H^{T} R^{-1} H\right)^{-1} H^{T} R^{-1} y
$$

This requires that values of $R$ and $H$ are known. The sensor noise covariance matrix can be computed analytically if the noise is easily quantifiable or numerically based on historical engine data. Because the sensor noise changes based on operating condition, $R$ will change as the operating point changes. More importantly, since the engine is highly nonlinear as a function of flight condition and operating point, the fault influence coefficient matrix, $H$, will be different at different conditions.

The fault influence coefficient matrix is essentially a linear relationship between the LPC health parameters and the corrected sensor residuals. $H$ can also be thought of as the Jacobian of the nonlinear equation:

$$
y=f(x)+w
$$

There are numerous techniques available to determine a value of $H$ that is appropriate to the current operating point. If a high fidelity, non-linear, model is available, the value of $H$ for a given flight condition, engine age, or deterioration level can be computed and stored on-board. However, with the motivation of applying this algorithm to existing hardware, a less memory intensive mechanism is proposed.

Given, a high-fidelity, off-line model, each of the LPC health parameters is perturbed by a small amount (1.0 percent) and the resulting steady-state changes in the corrected sensor residuals are measured. Since, in this particular case, there are two health parameters and two sensor residuals, $H$ is a $2 \times 2$ matrix. For example, the $(1,1)$ element of $H$ is the linear impact of a change in LPC efficiency on the corrected fan speed residual, computed as the change in corrected fan speed divided by the perturbation in LPC efficiency.

Examining Figure 1 the relationship between the corrected fan speed and the change in LPC performance as ice accretes is observed. To determine how much $H$ changes based on operating point a series of simulations is conducted at various 

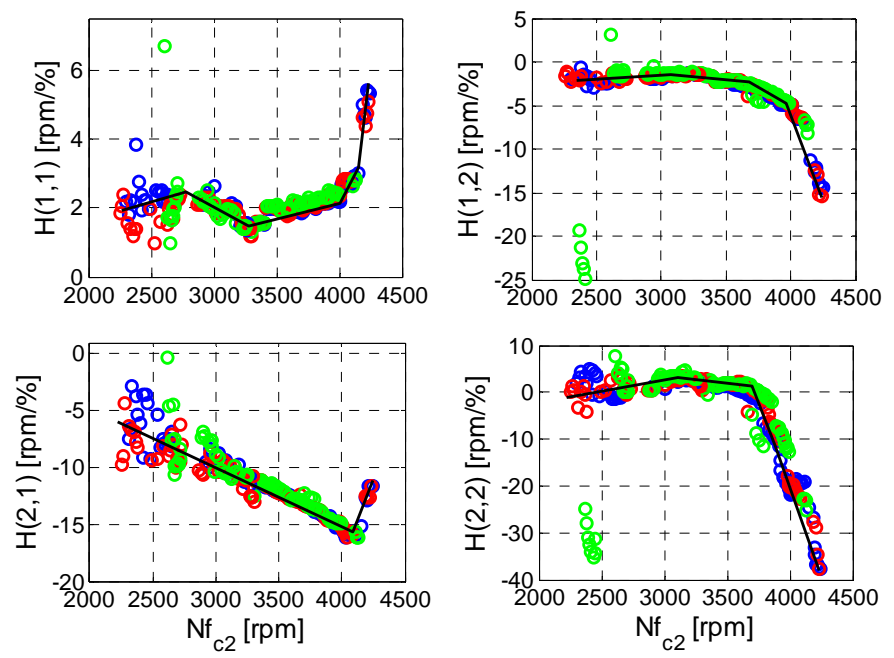

Figure 3.-The values of the fault influence coefficient matrix, $H$, for the C-MAPSS40k application as a function of altitude, Mach number, and engine power. The black line represents the piecewise-linear curve fit to the data. Blue points are at Mach 0.4, red at Mach 0.6, and green at Mach 0.8.

altitudes, Mach numbers, and power levels. The resulting values of each of the four elements of $H$ for the C-MAPSS40k application are plotted in Figure 3. Each color is a different Mach number (blue: Mach 0.4, red: Mach 0.6, and green: Mach 0.8). Altitudes from 10,000 to $30,000 \mathrm{ft}$ are shown as are the complete range of engine power levels. Note that the $\mathrm{x}$-axis of the plots is the corrected fan speed. When plotted in this manner there is a visible pattern to the data. For an initial implementation, a simple, one-dimensional interpolation (using fewer than six data points each) is used for each of the four elements of $H$. The black line in each of the plots shows the "fitted" line used for the interpolation. While there are many points far from the "fitted" line, this rough approximation is adequate, as will be seen later on, for the purposes of ice accretion detection at this preliminary stage.

With values of $y, R$, and $H$, it is now possible to compute the estimated health parameter shifts using Equation (2). With this estimate, detection logic must be applied. Once the logic output exceeds a threshold (thresh) for a predefined number of controller time steps, the "ice accretion" fault will be triggered. While there are many possible detection logics, two are chosen and examined in this paper:

$$
\begin{gathered}
\mathrm{LPC}_{\text {flow }}<\text { thresh }_{1} \\
\mathrm{LPC}_{\text {flow }}^{2}+\mathrm{LPC}_{\text {eff }}^{2}>\text { thresh }_{2}
\end{gathered}
$$

The first is simply the change in LPC flow capacity while the second uses the sum of the square of each of the estimated terms. Equation (4) is used based on the observation from the compressor map shown in Figure 1 that icing is associated with a decrease in LPC flow capacity. The sum of squares logic used in Equation (5) is a traditional detection logic that will track changes in the two parameters from zero.

\section{Example Application}

To determine the performance of the detection algorithm, it is applied to the C-MAPSS40k engine simulation. Based on the current value of the corrected fan speed, the appropriate value of $H$ will be determined via interpolation in accordance with the curve fit information shown in Figure 3. The sensor noise covariance matrix is assumed to be constant and is numerically computed for an operating point in the middle of the anticipated engine icing envelope. The detection logic is then applied to the estimated health parameters. If the logic returns a "true" then a counter is incremented. Once the "true" condition persists for a predetermined number of time steps, the fault condition is annunciated. The duration chosen is influenced by the frequency of sensor disturbances (sensor noise, turbulence, etc.). In this work, where the detection logic sample rate was synchronized with the C-MAPP40k controller time step of 0.015 sec, 67 consecutive time steps (approximately $1 \mathrm{sec}$ ) were required. When the engine inputs are no longer in steady state, the long window time averaged values are reset and the computation is restarted once steady state is reached.

In order to evaluate the effectiveness of the detection strategy, a 10,000 run Monte Carlo simulation is conducted using C-MAPSS40k. Each of the simulations is $4 \mathrm{~min}$ long. Half have no engine icing, and half experience a 2 min ice accretion from 0 percent blockage to 27 percent blockage. Each of the simulations is conducted at a steady, but random altitude, Mach number, ambient temperature, and power level. The flight conditions are randomly distributed across the envelope at which it is believed ice accretion can occur. Further each simulation uses an engine that is a different "age" (level of normal engine deterioration between new and end-oflife) and also includes typical engine-to-engine variation. This variation means that each engine has slightly different performance of each of the turbomachinery components. These random variations are typical of engines found in large commercial fleets (Ref. 12).

To determine the performance of this detection algorithm, these 10,000 Monte Carlo tests are run through the algorithm. Since the detection performance is directly related to the detection threshold, the threshold is varied. For each detection threshold, the true positive and false positive rates are computed and plotted in Figure 4. Each threshold tested produces a single point (marked with an $x$ ) and the lines are generated by varying the threshold from near zero to a large value. Due to the similarity of the two curves, a "zoomed-in" inset is shown to highlight the difference.

This type of plot is known as a Receiver Operating Characteristic (ROC) curve (Ref. 13). The ideal detection algorithm will enclose an area under the curve of one (capable of achieving a true positive rate of 100 percent while a 0 percent false positive rate). The detection logic of Equation (4) achieves this goal. Specifically, a threshold of -0.6 percent using the logic of Equation (4) has a true positive rate of 100 percent and a false positive rate of 0.0 percent. 


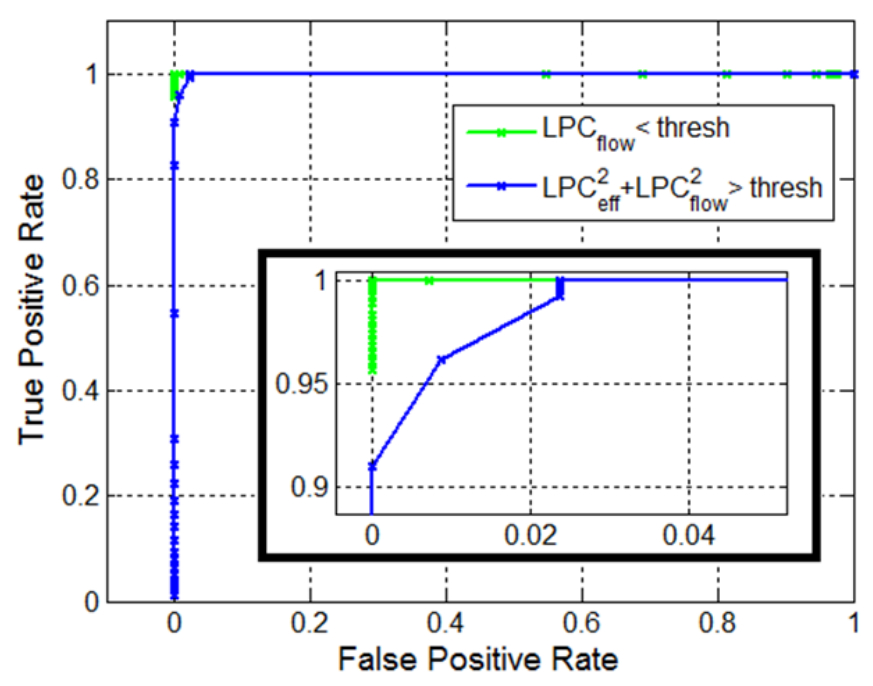

Figure 4.--Receiver operating characteristic curve for two detection logics used to detect the accretion of ice in the engine LPC. The inset is a magnified view of the upper left corner of the plot.

Interestingly, the logic of Equation (4) exceeds the performance of Equation (5). It was anticipated that the second detection logic will be more effective as it makes use of all of the available information; however this intuition proved to be incorrect. During non-iced operation, the distances should always be zero (or near zero) and then increase in magnitude as the ice accretes in the LPC and causes a shift in the health parameters.

Note that while the left hand side of the second detection logic (Eq. (5)) is always positive, the same is not true for the logic given in Equation (4). Based on the data in Figure 1, the flow capacity of the LPC always decreases during ice accretion (which agrees with common intuition). Thus, this threshold will be a negative number. Throughout the rest of the paper the magnitude of the threshold is shown in plots to allow for more direct comparisons. Including the sign of the change in flow capacity improves the specificity of the fault detection as a different fault that manifests as an increase in flow capacity would not trigger the detection using Equation (4), but might when using Equation (5).

In addition to true and false positive rates, it is important to determine when the detection occurs. The mean blockage at which detection occurs is plotted for each threshold value in Figure 5. As expected, as the magnitude of the threshold increases, the detection latency increases. Additionally, for any given threshold value, the mean blockage at detection using the detection logic of Equation (4) (decrease in flow capacity) performs better than almost all threshold values used with Equation (5) (sum of squares). Using the threshold of -0.6 percent (perfect detection using Equation (4)) results in detecting blockages at an average of 6.80 percent blockage, no non-zero threshold will produce earlier average detection when used with Equation (5).

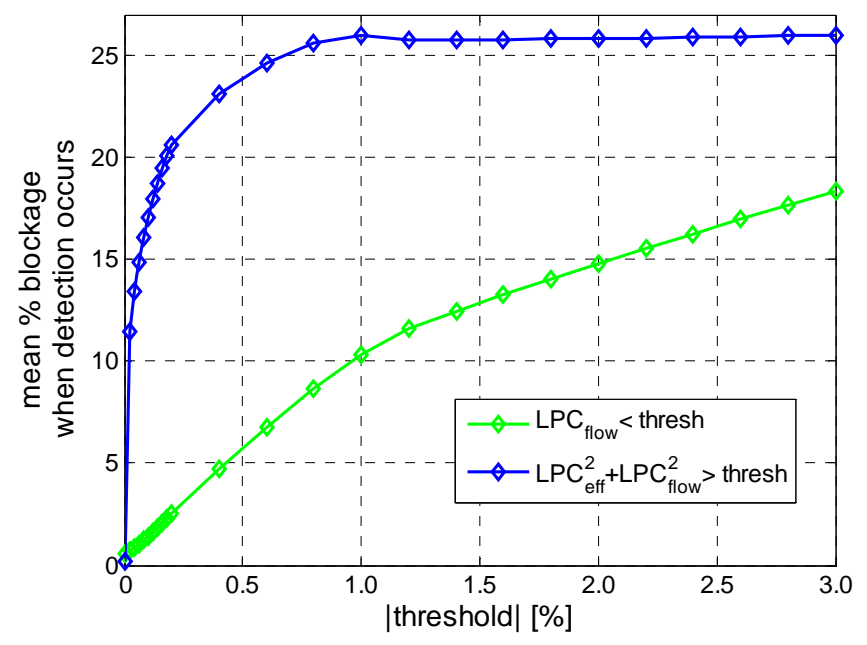

Figure 5.-Mean ice blockage level when icing fault is annunciated for various detection thresholds using the detection logic of both Equations (4) and (5).

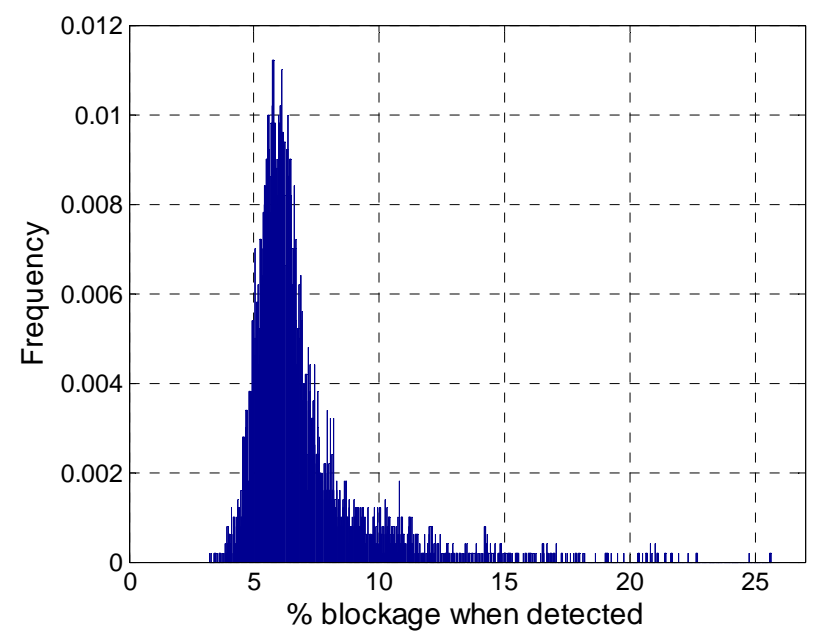

Figure 6.-Histogram of the ice blockage level when detection occurs using the detection logic of Equation (4) and a threshold of -0.6 percent. Ice accretion reaches 27 percent blockage in $2 \mathrm{~min}$.

In addition to the mean, the complete distribution of ice blockage level when the fault is annunciated is important to know. This is shown in Figure 6 for the case where Equation (4) is used for detection and the threshold value is -0.6 percent. Again, the mean blockage when detected is 6.80 percent with a standard deviation of 2.20 percent and a maximum of 25.63 percent. From this data we can compute the probability that detection will occur before a specific blockage level is reached. For example, in 92.62 percent of the cases tested, the blockage is detected prior to reaching 10 percent. This becomes useful if other studies highlight a particular blockage threshold that should not be exceeded prior to the initiation of mitigation strategies. For example, if it is necessary to begin mitigation efforts prior to 15 percent blockage, then approximately 1.5 percent of cases shown in Figure 6 would be detected too late. 


\section{Practical Considerations}

The fact that this detection algorithm worked extremely well in the Monte Carlo analysis conducted here does not guarantee that it will perform well in practice. One of the largest drawbacks of this algorithm is the fact that the engine inputs (operating point and throttle) must all be constant in order to detect the accretion of ice. While we have no data at the moment on the environmental disturbances encountered while operating in the HIWC conditions typically associated with convective storms, the presence of turbulence is nearly certain.

If the frequency of these disturbances is higher than that of the sensor noise, then there should be minimal loss in performance as the detection algorithm requires that the conditions persist for some predefined period of time (here we used $1 \mathrm{sec}$ ), essentially serving as a low pass filter. The length of this window can be increased if necessary to separate the frequency at which the airframe disturbances occur from those of the icing detection. For example, when using a window of 5 sec, 100 percent true positive rate and 0 percent false positive rate detection is again achieved at the cost of increasing the mean blockage at detection to 8.30 percent. Further increasing the length of the window to $10 \mathrm{sec}$ results in 0.0 percent false positive rate, a 99.96 percent true positive rate, and mean blockage at detection of 9.51 percent. In general, these disturbances would delay detection as well as increase the rate of false positives. Without further information, it is difficult to determine if this decrease in performance is acceptable.

In addition to the environmental disturbances causing transients, icing frequently occurs during the descent phase of flight (Ref. 1). Generally during descent operation the aircraft speed and glide slope are kept relatively constant, typically a 1,000 to $4,000 \mathrm{ft} / \mathrm{min}$ descent. Since ice accretion is on the order of minutes, these potentially large changes in altitude would violate the steady-state assumption that is critical to this detection algorithm.

Another variable is the ice growth rate. While small scale icing studies have been done (Ref. 14), it is unclear how quickly ice accretes in the engine compressor. To address this area of uncertainty, another Monte Carlo study, comprised of 1,000 cases, was conducted. In addition to the variability in the earlier study, the ice accretion time is random, uniformly distributed between 1 and $5 \mathrm{~min}$. Using the detection logic of Equation (4) with the threshold of -0.6 percent the true positive rate is 100 percent for these additional test cases. The distribution of the blockage level at the time of detection is shown in Figure 7. This distribution is similar to that of Figure 6 except that the mean is slightly higher (8.00 versus 6.80 percent) and the standard deviation is lower (1.87 versus 2.20 percent).

Due to the construction of the linear filter, all changes in engine performance are ascribed to changes in the LPC characteristics. While it is possible to increase the size of $x$ to include the health parameters of other engine components, this will increase the size of $H$ as well as the fidelity necessary.

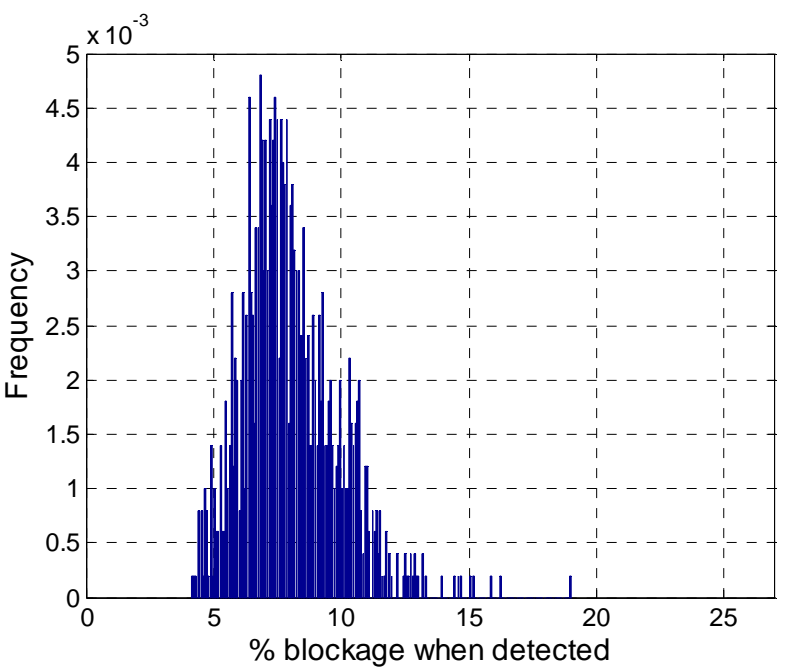

Figure 7.-Histogram of the ice blockage level when detection occurs using the detection logic of Equation (4) and a threshold of -0.6 percent. Ice accretion rate is uniformly randomly distributed and reaches 27 percent blockage between 1 and 5 min.

In order to maintain the proposed structure, it is possible to determine how well the estimation process is working by estimating the sensor residuals using the estimated health parameters by substituting $x=\hat{x}$ and $w=0$ into Equation (1) to obtain

$$
\hat{y}=H \hat{x}
$$

This estimated vector of sensor residuals then allows for a "sanity check" because the difference between the actual and the estimated residuals should be small. This check can be useful for determining when the detection algorithm should not be running due to an unexpected problem. For example, when a fault has occurred in an engine component or the $H$ matrix is not appropriate to the current operating point. While this cross check was not implemented in this work (as it has no bearing on the performance of the detection algorithm) it is expected to be used in any fully-developed detection system.

Another practical implementation issue is the question of how accurate the icing models implemented in C-MAPSS40k are. An engine altitude test facility at NASA Glenn, known as the Propulsion Systems Laboratory, is undergoing modifications to facilitate engine icing tests. Testing in this facility should enable ice accretion model verification. Work must also be done to characterize the disturbances encountered during flight in high ice water content conditions which should be provided by an upcoming NASA flight campaign planned to occur in Darwin, Australia. Overall, this detection algorithm handles the expected in-flight variation including engine deterioration, engine-to-engine variation, flight condition, power level, and ice accretion rate. The impact of disturbances in altitude, speed, and power level on detection performance is not able to be determined at this point due to the lack of flight data in these HIWC conditions. The detection of ice accretion 
during descent proves to be a challenge due to the fact that the sink rates are high enough to produce large shifts in engine performance.

\section{Mitigation of Icing}

There are two possible engine control system mitigation strategies that can be applied once ice accretion has been detected in the engine core. The first is to change the engine operating point in such a way that the ice can no longer grow or possibly even start to melt. Potential means of achieving this goal is studied throughout this section. The other goal, which is not considered in this work, is to change the engine operating point in order to preserve safety margin and (to a lesser extent) engine performance.

At the present time it is unclear what techniques are effective at preventing or mitigating ice accretion. However, it is believed that the accretion can only occur under a relatively narrow range of temperature, ice water content, and liquid water content conditions (Ref. 8). Thus, it is anticipated that changing the engine operating point to a higher (or lower) LPC temperature can move the engine outside of this range.

The impact of any change to the engine operating point is heavily dependent on the nature of the engine control system. Due to the lack of a thrust measurement, most engines use either fan shaft speed or engine pressure ratio (EPR), turbine outlet pressure divided by engine inlet pressure, as the controlled variable. The engine controller will regulate the fuel flow rate to maintain the desired setpoint (either fan speed or EPR). All of the following work uses an EPR controlled engine.

To change the temperature of the air in the LPC, one must increase (or decrease) the amount of work being done on the air by the compressor. To increase the temperature, the compressor must operate at a higher speed, which also produces more thrust. This can be done by increasing the throttle or by closing any inter-compressor bleed valves. To decrease the temperature, the throttle can be decreased or bleed valves opened.

To evaluate the impact of these changes an engine simulation like C-MAPSS40k can be used. Unfortunately, this simulation does not model individual compressor stages so only LPC inlet and outlet temperatures are available; LPC metal temperature is calculated as well but, in steady-state, is simply an average of the inlet and outlet gas temperatures. During transients, the heat convection is modeled which results in slower changes. Additionally, there is no ice accretion physics modeled in C-MAPSS40k. Thus, this simulation can be used to test potential control law changes, but in-depth evaluations require a more detailed simulation.

The engine modeled in C-MAPSS40k is a typical twin-spool turbofan engine as shown in Figure 8. The primary actuator is the fuel metering valve and secondary actuators are the station 25 bleed (also known as the inter-compressor bleed, variable bleed valve (VBV)) and the high pressure compressor (HPC) variable stator vanes (VSV) or inlet guide vanes.

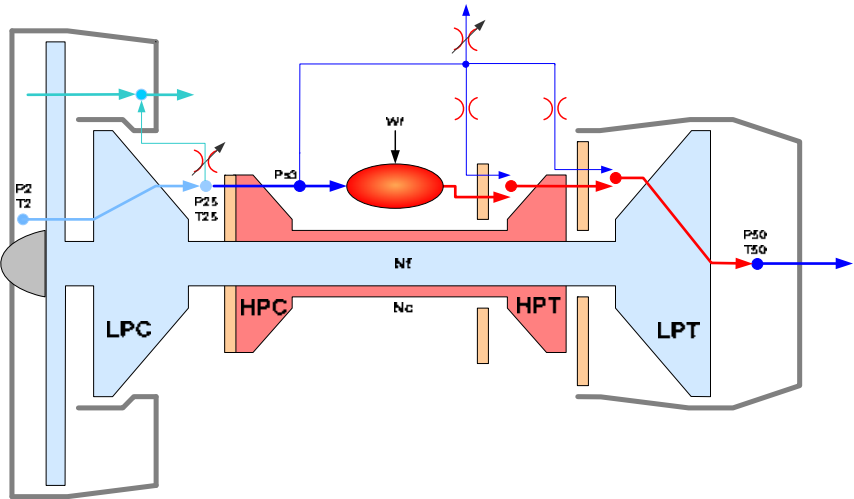

Figure 8.-Schematic of the engine modeled in C-MAPSS40k. reproduced from Reference 5 .
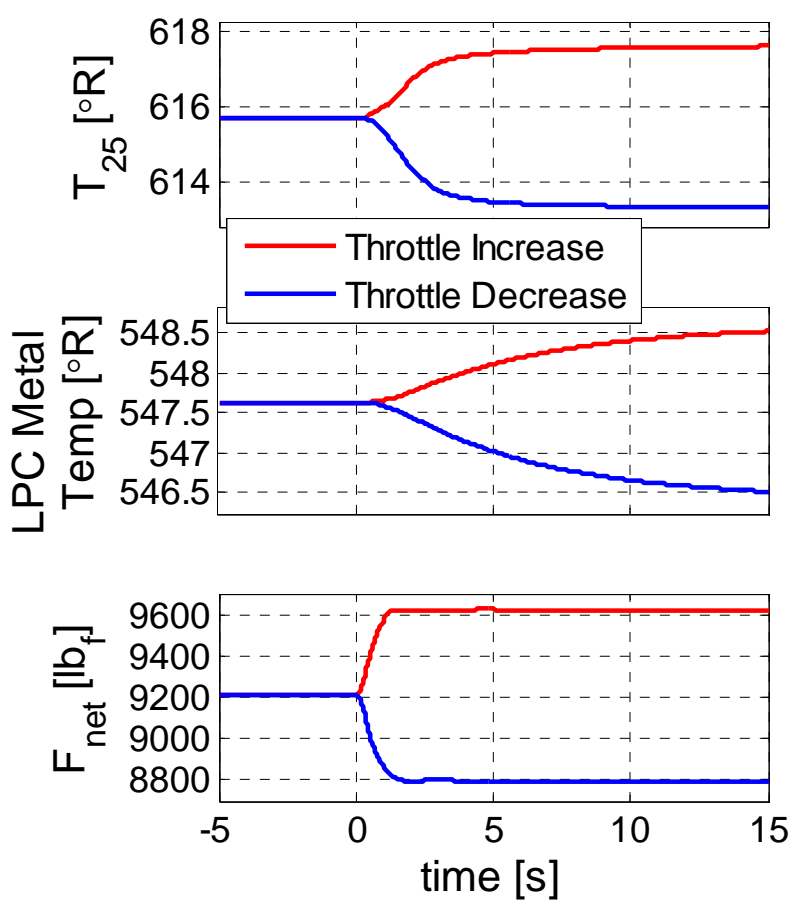

Figure 9.-Engine response to $\mathrm{a} \pm 1^{\circ}$ throttle transient at $0 \mathrm{sec}$. The flight condition is at $20,000 \mathrm{ft}$, Mach $0.6,60^{\circ}$ throttle.

By modifying these various actuator positions, we can observe the effect on the LPC metal temperature as well as the gas temperature. The following simulations are conducted at a steady-state condition within the icing envelope $(20,000 \mathrm{ft}$, Mach 0.6, and 50 percent throttle). In this first case, shown in Figure 9, a $\pm 1^{\circ}$ throttle step change occurs at 15 sec. The resulting changes in LPC outlet temperature $\left(\mathrm{T}_{25}\right)$, LPC metal temperature, and thrust are shown. The change results in a $\pm 2{ }^{\circ} \mathrm{R}$ change in outlet gas temperature and a $\pm 1{ }^{\circ} \mathrm{R}$ change in the LPC metal temperature. As expected, there is a change in net engine thrust. At the present time it is unclear if this change in temperature is enough to have any impact on the ice growth rate. 

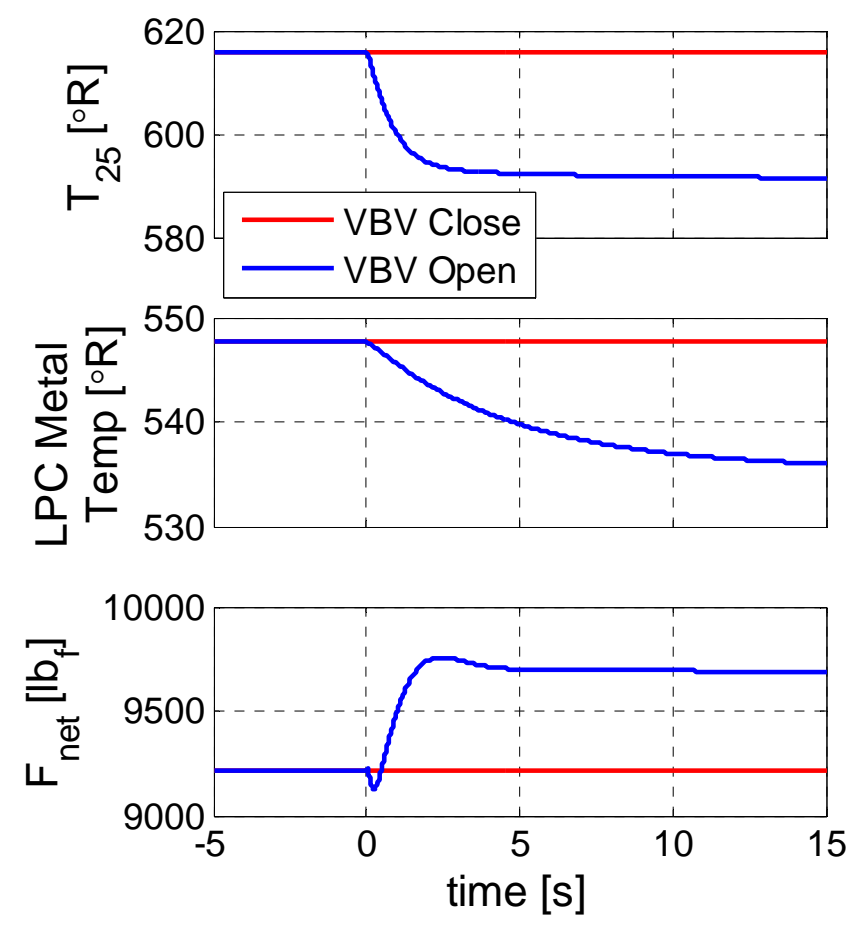

Figure 10.-Engine response to a VBV open and VBV close transient at $0 \mathrm{sec}$. The flight condition is $20,000 \mathrm{ft}$, Mach $0.6,60^{\circ}$ throttle.

When the VBV is commanded to be fully open (or closed), there is a change in pressure at the outlet of the LPC. This results in changes to the engine setpoint and thus an eventual increase or decrease in fuel flow rate. The results are shown in Figure 10. There is a significant change in operating point when the VBV is fully opened-a roughly $-30{ }^{\circ} \mathrm{R}$ change in gas temperature associated with an increase in engine thrust. This thrust change is due to the fact that bleeding air off the engine core flow decreases EPR, so the control system increases the fuel flow rate, speeding up the engine and increasing thrust. Surprisingly, there is no change when the VBV is closed fully. This turns out to be caused by the fact that steady-state VBV position is almost closed (10.8 percent open), so closing the valve the rest of the way results in an insignificant change in engine performance. This highlights a potential problem when using the VBV to mitigate ice accretion. There is some nominal VBV position to produce safe compressor surge margins. Thus, if the VBV is fully opened or closed there may not be much of a change in the actual position. In addition, these off-nominal changes result in reduced compressor surge margin for either the LPC or HPC at a time when the margin may already be reduced due to icing effects (as shown in Fig. 1).

Lastly, when a $5^{\circ}$ positive and negative shift is introduced into the variable stator vanes, the resulting engine outputs are shown in Figure 11. The VSV are used to achieve optimal HPC efficiency during all stages of operation; by shifting them off-nominally fuel efficiency is lost. Small $\left(<1^{\circ} \mathrm{R}\right)$ changes in
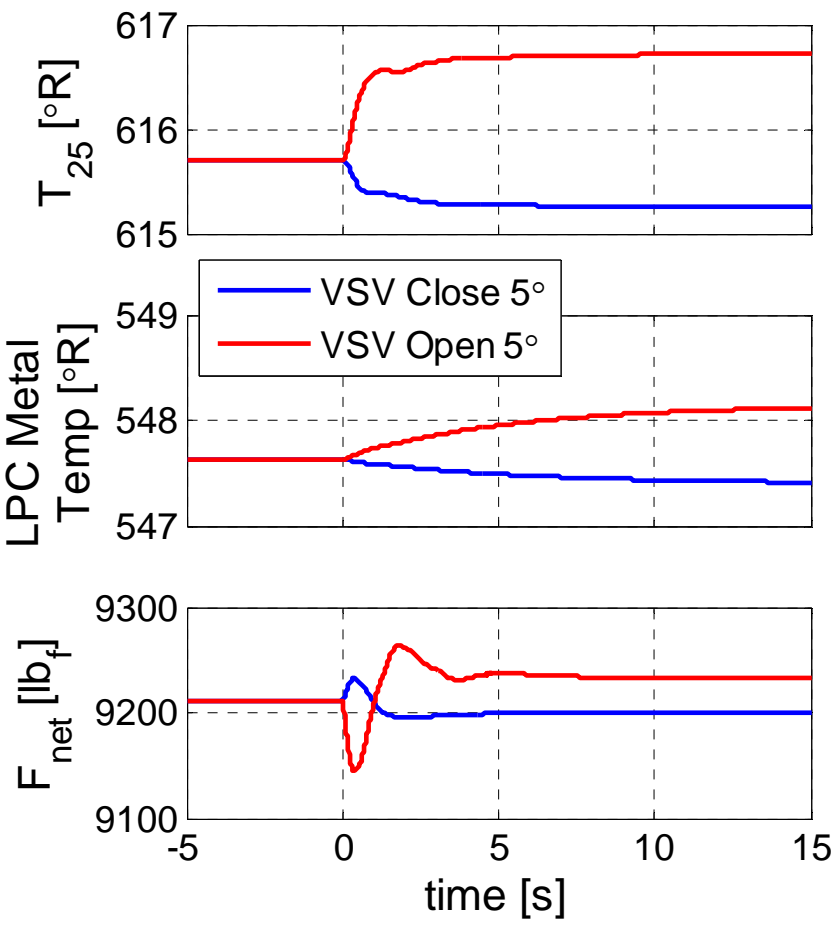

Figure 11.-Engine response to a positive and negative $5^{\circ}$ VSV transient at $0 \mathrm{sec}$. The flight condition is $20,000 \mathrm{ft}$, Mach $0.6,60^{\circ}$ throttle.

outlet gas temperature result along with minimal change in engine thrust and compressor surge margin.

Depending on the size of the change in operating condition necessary to prevent ice accretion, a combination of these changes may need to be employed. Ideally, there would be no thrust change, but the thrust change may be acceptable if it mitigates the icing. As every engine is different, alternate actuators may be available that are more effective. Each would need to be studied on a case-by-case basis. Regardless, even a simple change such as modifying the throttle leads to changes in LPC temperature and may be useful to mitigate engine ice accretion.

Means to mitigate ice accretion remains a large challenge. The proposals put forth in this paper need to be tested in a simulation environment capable of simulating the physics of ice crystals entering the compressor. As the fundamental physics work continues, it is expected that more refined models about the conditions necessary for ice accretion will become available. This information will then determine the direction of mitigation efforts.

\section{Conclusions}

An algorithm designed to detect the accretion of ice in the low pressure compressor (LPC) of an aircraft engine was developed. This algorithm was then applied and tested on a 40,000 lbf thrust class engine simulation. This approach uses a low memory footprint linear estimator to estimate the changes 
in efficiency and flow capacity of the LPC during steady-state operation. A number of detection logics were then tested, two of which were presented here. An approach relying on monitoring for decreases in the estimated flow capacity was found to perfectly discriminate between icing and non-icing events using a 10,000 case Monte Carlo analysis of engines operating across the flight envelope and at different power levels, deterioration levels, and accounting for engine-toengine variation. An initial overview of potential mitigation capabilities of the existing engine actuators was then conducted and found that it is possible to alter the conditions inside the LPC by varying the actuators from the nominal schedule.

\section{References}

1. Fisher, J., "Aircraft Turbine Engine Icing: Current Issues and Future Vision," Presentation at SAE International Conference on Aircraft and Engine Icing and Ground Deicing, Chicago, IL, Jun 16, 2011.

2. Mason, J., "Current Perspectives on Jet Engine Power Loss in Ice Crystal Conditions: Engine Icing," Presentation at 2008 AIAA Atmospheric and Space Environments, June 23rd, 2009.

3. Jorgenson, P.C.E., Veres, J.P., May, R.D., Wright, W.B., "Engine Icing Modeling and Simulation (Part 1): Ice Crystal Accretion on Compression System Components and Modeling its Effects on Engine Performance," 2011-38-0025, SAE International Conference on Aircraft and Engine Icing and Ground Deicing, Chicago, IL, Jun 13-17, 2011. doi:10.4271/2011-38-0025.

4. May, R.D., Guo, T-H., Veres J.P., Jorgenson, P.C.E., "Engine Icing Modeling and Simulation (Part 2): Performance Simulation of Engine Rollback Phenomena,” 2011-38-0026, SAE International Conference on Aircraft and Engine Icing and Ground Deicing, Chicago, IL, Jun 13-17, 2011. doi:10.4271/2011-38-0026.

5. May, R.D., Csank, J., Lavelle, T.M., Litt, J.S., and Guo, T.H., "A High-Fidelity Simulation of a Generic Commercial Aircraft Engine and Controller,” AIAA2010-6630, 2010 AIAA Joint Propulsion Conference, Nashville, TN, July, 2010.
6. Csank, J., May, R.D., Litt, J.S., Guo, T.H., “Control Design for a Generic Commercial Aircraft Engine," AIAA-2010-6629, 46th AIAA Joint Propulsion Conference \& Exhibit, Nashville, TN, July, 2010.

7. Armstrong, J.B., Simon, D.L., "Implementation of an Integrated On-Board Aircraft Engine Diagnostic Architecture," AIAA-2011-5859, NASA/TM-2012217279, 47th AIAA Joint Propulsion Conference and Exhibit, San Diego, California, July 31-August 3, 2011.

8. May, R.D., Simon, D.L., Guo, T.H., “Modeling and Detection of Ice Particle Accretion in Aircraft Engine Compression Systems,” AIAA-2012-4649, AIAA Atmospheric Flight Mechanics Conference, Minneapolis, Minnesota, August 13-16, 2012.

9. Currie, T., Knezevici, D., MacLeod, J., Fuleki, D., "Particle Size Effects on Ice Crystal Accretion," AIAA-2012-3039, AIAA Atmospheric Flight Mechanics Conference, Minneapolis, Minnesota, August 13-16, 2012.

10. Simon, D.L., Litt, J.S., “A Data Filter for Identifying Steady-State Operating Points in Engine Flight Data for Condition Monitoring Applications,” NASA/TM2010-216359, ASME Journal of Engineering for Gas Turbines and Power, July 2011, Volume 133, Issue 7.

11. Kay, S., Fundamentals of Statistical Signal Processing, Volume 1: Estimation Theory, Prentice Hall, 1993.

12. Sallee, G.P., "Performance Deterioration Based on Existing (Historical) Data - JT9D Jet Engine Diagnostics Program,” NASA Contractor Report CR135448, United Technologies Corporation, Pratt \& Whitney Aircraft Group Report PWA-5512-21, 1978.

13. Fawcett, T., "An Introduction to ROC Analysis," Pattern Recognition Letters, vol. 27, pp. 861-874, 2006.

14. Struk, P., Currie, T., Wright, W., Knezevici, D. et al., "Fundamental Ice Crystal Accretion Physics Studies," 2011-38-0018, SAE International Conference on Aircraft and Engine Icing and Ground Deicing, Chicago, IL, Jun 13-17, 2011. doi: 10.4271/2011-380018. 


